\title{
Opportunities and impediments for use of local data in the management of salmon fisheries
}

\author{
$\underline{\text { Sarah C. Inman }}^{1}, \underline{\text { Janessa Esquible }}^{2}, \underline{\text { Michael L. Jones }}^{3}$, William R. Bechtol $^{4}$ and $^{\text {Brendan Connors }}{ }^{5}$
}

\begin{abstract}
Data availability challenges the management of small-scale fisheries in large river basins. One way to circumvent the challenges of data collection is to rely on local stakeholders who are well-positioned to collect data that can inform management through community-based monitoring (CBM). Although science and management has increasingly considered opportunities for community involvement in scientific research, the efficacy of these programs are rarely assessed. We describe a current CBM initiative in the Kuskokwim River Basin of western Alaska. We then explore how existing approaches for incorporating local involvement in fisheries research and management measure against claims made by CBM programs to understand pathways for data utility for decision makers and approaches to capacity building and meaningful engagement of local citizens. We identify major gaps in the CBM literature and explore one of these gaps through an interview-based study of public participation in the Kuskokwim. We find that the CBM program intent to collect high quality data was complemented by increasing trust in data stewards. Ultimately, through our interview findings we illustrate how definitions of local engagement differ, how CBM data is used by decision makers, and how trust in data is dependent on trust in data stewards and the infrastructure that supports that stewardship.
\end{abstract}

Key Words: Alaskan salmon; community-based monitoring; coproduction of scientific knowledge; natural resource management

\section{INTRODUCTION}

Public engagement in scientific research is a growing practice in natural resource management as research has shown the importance of incorporating local participation (Theobald et al. 2015); however, the data produced by these programs are often underutilized (Conrad and Hilchey 2011, Buckland-Nicks et al. 2016) disincentivizing public engagement in scientific research. This dynamic is particularly relevant in the Arctic-YukonKuskokwim (AYK) region of Alaska, which is remote, vast, and vulnerable to climate change as many people depend on the resources of the land and sea at physical, mental, and spiritual levels (National Research Council 2005). We focus our study on the subsistence Chinook salmon (Oncorhynchus tsawytscha) fishery in the Kuskokwim River to highlight challenges that are often common to fisheries management, namely, managing in a remote region with high costs of stock assessment. Through interviews, we examine how the Alaska Department of Fish and Game (ADF\&G), U.S. Fish and Wildlife Service (USFWS), and Tribal in-season managers, all of whom share management responsibility for the Kuskokwim River (Fig. 1) subsistence salmon fisheries, interact with local, mainly Indigenous, harvesters. Specifically, we focus on how data are used to inform in-season management decisions, how community-based monitoring $(\mathrm{CBM})$ - the practice of involving local people in the identification and monitoring of community concernscontributes to this process, and what influence CBM might have on the relationship between harvesters and managers.

With this paper we contribute an understanding of how different scales of governance-tribal, nontribal, state, and federal managers negotiate challenges of management within an Alaska salmon fishery and how locally collected data mediate these deliberations. We explore how locally generated data are made tractable to natural resource managers. First, we review literature on current CBM initiatives in fisheries for a deeper understanding of how current approaches measure against claims made about CBM programs to understand pathways for data usability by decision makers, and to inform our interview design. Then, we interview decision makers in the area about their assessment of data usability and how they measure salmon abundance. This work examines the ways that local, mainly Indigenous, people and scientists work together to achieve their goals and to highlight best practices for engaging people in the monitoring of natural resources.

Management of the salmon fishery in the Kuskokwim River Basin (hereafter referred to as the Kuskokwim) in recent decades has been informed by Western, scientific knowledge of salmon population dynamics and fishery systems, which attempts to overcome uncertainty by applying well-known statistical models of fisheries (Hamazaki et al. 2012, Staton et al. 2017, 2020, Connors et al. 2020). This type of natural resource management involves state and federal managers with a background in biology and statistics who base decisions on the interaction between three key factors: (1) stock-recruitment dynamics of the salmon population under management; (2) expected run size; and (3) the relationship between fishing regulations and harvest. The first factor informs selection of an escapement goal, a target number of adult salmon needed to reproduce each year to provide sustainable future returns. The second factor determines how much harvest can be taken within a given year without risking failure to meet the escapement goal. Finally, the third factor allows managers to specify the necessary conditions to maintain the harvest within target bounds. All factors depend on a retrospective view of harvest and stock responses to previous management actions.

In the Kuskokwim, there is also a form of comanagement in which in-season managers representing the Kuskokwim River Intertribal Fisheries Commission (KRITFC) contribute to decisions about fishery openings and closures during each fishing season. Throughout Alaska, most salmon fisheries are managed

${ }^{1}$ Human Centered Design and Engineering, ${ }^{2}$ Orutsararmiut Traditional Native Council, ${ }^{3}$ Michigan State University, Department of Fisheries and Wildlife, Quantitative Fisheries Center, ${ }^{4}$ Bechtol Research, ${ }^{5}$ Institute of Ocean Sciences, Fisheries and Oceans Canada 
Fig. 1. Map of Alaska. The Kuskokwim region is located in the southwest corner of Alaska. Image from Alaska Department of Fish and Game.

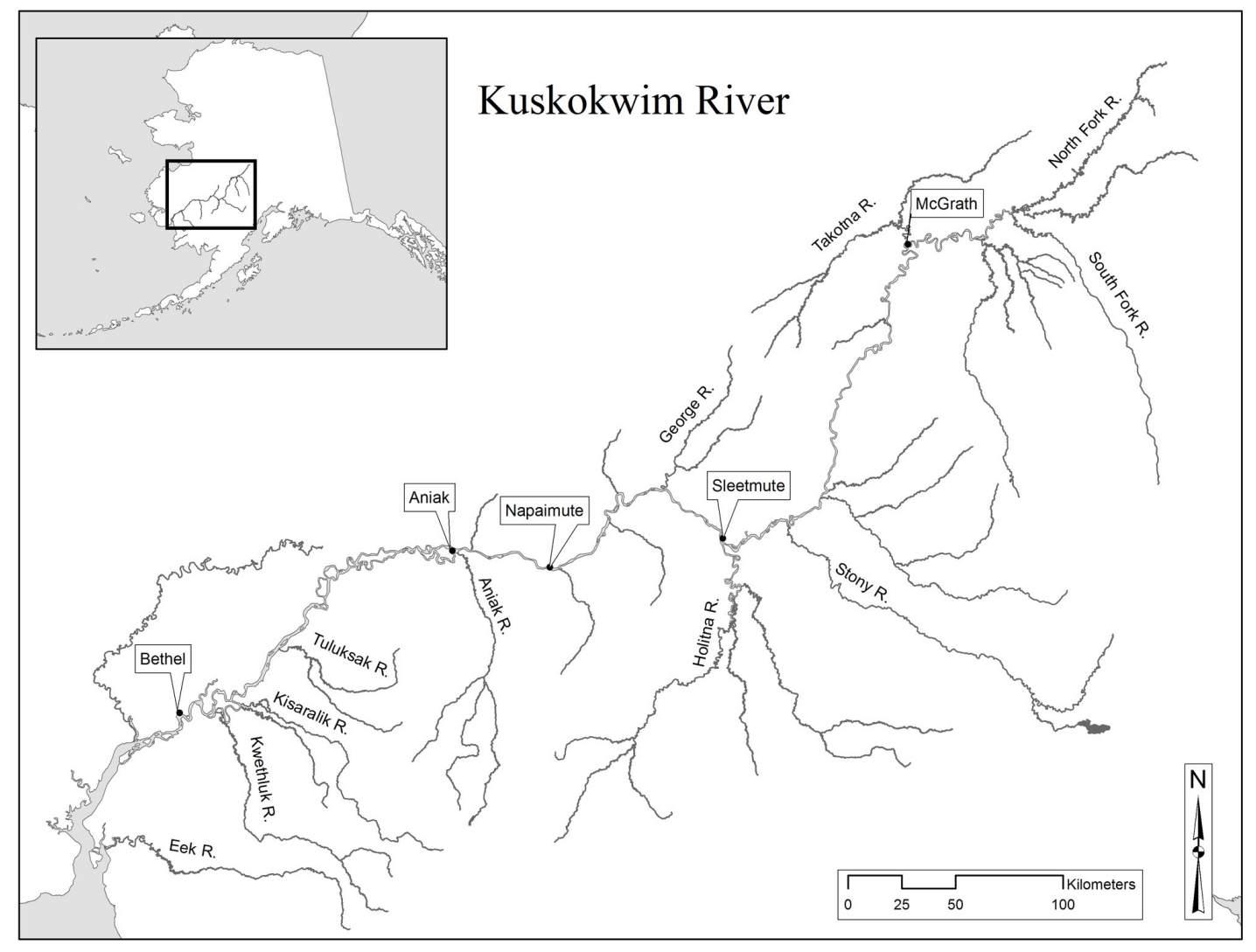

by the State of Alaska through designation to ADF\&G managers with no priority for subsistence harvests among Alaska residents. Section 802 of the Alaska National Interest Lands Conservation Act (ANILCA), a federal measure, established a rural priority for subsistence harvest on federal waters, and the U.S. Congress anticipated the State of Alaska would implement this rural subsistence priority. However, a 1989 Alaska Supreme Court decision found the rural priority in conflict with the common use clause of the Alaska Constitution. Section 804 of ANILCA clarifies that when necessary to restrict subsistence harvests on federal lands in order to protect the continued viability of [fish and wildlife] populations, or to continue such uses, a subsistence priority will be implemented based on, (1) customary and direct dependence upon the populations as the mainstay of livelihood; (2) local residency; and (3) the availability of alternative resources. In cases of ample resource abundance for subsistence uses in the Kuskokwim, the federal government typically defers management to the State of Alaska. However, in recent years of low Chinook salmon abundance, the federal government has assumed management of Chinook salmon harvests on federal waters of the Kuskokwim River. Under a Memorandum of Understanding (MOU) adopted in 2016, federal managers with USFWS, and under delegated authority from the Federal Subsistence Board, have implemented management measures in cooperative consultation with in-season managers of KRITFC. This cooperative agreement also seeks input from ADF\&G and an
ADF\&G advisory group: the Kuskokwim River Salmon Management Working Group (KRSMWG). The KRSMWG was founded in 1988 by the Alaska Board of Fisheries (BOF) as an advisory group with the goal of providing a mechanism for stakeholders to express a more active role in managing their salmon fisheries.

The Kuskokwim region accounts for the highest subsistence Chinook salmon harvest in Alaska. Chinook salmon abundance decline has led to reductions to commercial, recreational, and subsistence salmon fishing, which subsequently curtailed data input. However, CBM programs have filled this gap with a focus on informing in-season management, supporting equitable harvest opportunities, promoting more inclusive management, and involving stakeholders in assessment and management processes. As recent as 2017, KRITFC and the Bering Sea Fishermen's Association (BSFA) initiated a CBM program to monitor harvest in lower river Kuskokwim communities where the majority of Chinook salmon harvest occurs. These efforts were designed after the Orutsararmuit Traditional Native Council's (ONC) long-term monitoring program. ONC is the federally recognized Tribal governing body for the Tribal citizens of Bethel, and ONC has a government to government relationship with the United States government. Since 2001, ONC has conducted Kuskokwim in-season subsistence catch monitoring in Bethel with ADF\&G. Concurrently, studies found a reduction in both size-at-age and also the proportion of older age classes of 
Chinook salmon (Evenson et al. 2009, Lewis et al. 2015) compounding impacts of declining run size. Growing concerns about these changes led to calls for research (Schindler et al. 2013) to shed light on causes of declines in Chinook abundance. One strategy that emerged centered on increased use of CBM to inform management, which resulted in a pilot CBM project in the lower Kuskokwim.

Our study area encompassed the lower Kuskokwim River and focused on the Chinook salmon fishery. The Kuskokwim River stretches across 700 miles through Southwest Alaska, draining into the Bering Sea. The majority of the 16,000 residents of the Kuskokwim area live in the Kuskokwim River drainage, but this area also includes several Bering Sea coastal villages. The Yup'ik people are the predominant cultural group in the Lower Kuskokwim River, Yup'ik and Athabascan people in the middle Kuskokwim, and Athabascan people in the upper Kuskokwim. Salmon is a primary source of sustenance in subsistence communities throughout the Kuskokwim. However, salmon is much more than food. Within the Pacific Northwest and Alaska, salmon have immense cultural significance. As Kuskokwim resident and former KRITFC in-season manager, Nick Kameroff, commented in a podcast episode, "my relationship with salmon is my lifestyle" (https://www.nceas.ucsb.edu/news/ podcast-alaskas-exceptional-salmon-data), a refrain echoed throughout the region.

Although accurate monitoring and modeling is critical to successful science for environmental management, management success also depends on well-informed questions and on local adherence to management directives, which is directly impacted by the degree to which residents feel included in the process. Literature on public participation and natural resource management notes that local participation not only increases adherence to management policy decisions (Beierle and Konisky 2000, Ostrom 2000, Dietz et al. 2003, Baber and Bartlett 2005), but also creates opportunities for knowledge exchanges across disciplines, federal and state natural resource managers, and local and Tribal citizens. As such, scientific researchers and resource managers have brought the public into scientific research, data collection, and environmental decision making in more deliberative ways (Ostrom 1990). Rather than an objective set of findings, knowledge is dynamic, socially and technically produced, and ultimately, emerges from a collaborative effort (Edwards et al. 2013).

\section{LITERATURE REVIEW}

The ideas that inform this research come from two main bodies of work. First, we draw from the literature on locally derived information, which we generally refer to as community-based monitoring (CBM). Despite the myriad terms for community involvement in science, we selected CBM as a framework because it was the term most commonly used by research participants in the field. Relying on "actors' categories," or the words and terms most commonly used by research participants, is a long-standing tradition in ethnography as ethnographers look closely at what people do and say "paying particular attention to the words, phrases, and categories that members use in their everyday interactions" (Emerson et al. 2011:134). The second thread of research we draw from is the concept of coproduction in science and technology studies (STS) to shed light on how institutions constrain or enable the local scale production of data through community engagement.

\section{Community-based monitoring}

We reviewed the CBM literature by systematically searching two online database platforms: ProQuest and Google Scholar. For information about inclusion/exclusion criteria, coding variables, and sensitivities, and a full list of papers reviewed see Appendix 1. CBM refers to a process in which "concerned citizens, government agencies, industry, academia, community groups, and local institutions collaborate to monitor, track, and respond to issues of common community concern" (Whitelaw 2003:410), and CBM has been used in multiple sectors and regions to increase public engagement and leverage citizens' local expertise. Much of the literature on CBM has focused on local citizens, not specifically Tribal citizens. Furthermore, the usage of the term "citizen" assumes some controversy because it can suggest national citizenship. USDA Forest Service has suggested that the usage of "citizen" refers to something more akin to "global citizen," or a person interested in participating in science at a broader scale. In their suggestion of less problematic terms, they suggest knowledge coproduction.

Through synthesis of research focused on CBM in fisheries management, we identify areas that have been underexplored in CBM literature, and determine how insights from STS can expand on some of these areas. Based on our review, scholars use CBM in a variety of ways: to implicitly refer to community members' involvement in data collection, to integrate traditional tribal stewardship practices into fisheries management plans, and to help formulate goals of comanagement and coproduction of knowledge. While noting that CBM involves "monitoring of natural resources undertaken by local stakeholders ... in relation to aims and objectives that make sense to them," Danielsen et al. (2014:15) do not identify the ways that the aims and objectives differ for different groups involved. In more recent review studies, there is an increased awareness of the need for local stakeholders to be more meaningfully engaged in all steps of establishing and implementing a CBM program (Johnson et al. 2016).

Our review of the CBM literature revealed the following gaps:

1. The stated goals for CBM center around community engagement and connection to decision making; however, relatively few studies measure these proposed outcomes;

2. The monitoring is typically defined by the scientific observing community rather than locally situated communities, and data collected are primarily biological and quantitative; and

3. Little research has explored CBM data usability or how and when citizen-derived data are seen as useful to management.

The majority of the papers we reviewed cited decision-making support and empowering local citizens as the primary goals for CBM implementation. The primary data collected by community monitors are biological data, which is often because of contextual and environmental factors that render biological and quantitative data types easier to collect than qualitative data types such as interviews and ethnographic research. Unfortunately, data that serves the aims of existing management regimes do not always recognize the compartmentalization and distillation that occurs 
when traditional knowledge is used in existing management regimes, thus diminishing the value and integrity of local understanding (Nadasdy 2005).

\section{Coproduction in science and technology studies}

Much has been written about coproduction going back to Elinor Ostrom's usage of the term in the 1970s to refer to the critical influence that citizens have in the production and management of public services. Miller and Wyborn (2020) trace the multiple threads of coproduction illustrating the ways in which it has been used differently across public administration, STS, and sustainability science (Miller and Wyborn 2020). We take up the STS version of coproduction to explore scientific knowledge production from a social constructivist paradigm. In this view, scientific truths are not only the product of scientific organizations, but are distributed across other regulatory agencies, publics, and policy (Jasanoff 2004). In other words, knowledge is not something that is solely within individual actors or organizations but is rather a socially distributed achievement. For example, Hirsch (2020) explored the way that science and law have coproduced restoration in the Columbia River Basin highlighting the material and political ramifications of environmental management. As she states, this is largely because "knowledge about nature is co-produced along with societal actions to manage the environment and order nature" (Hirsch 2020:59). Knowledge about Alaska salmon ecosystems has historically emerged through the interactions between institutions like ADF\&G and USFWS as well as exchanges of knowledge through the KRITFC. In this research, we look more closely at how the exchange across Indigenous knowledge holders, quantitative ecologists, and natural resource managers coproduces knowledge about Alaska salmon.

Jasanoff (2004) identifies two particular threads of coproduction: constitutive and interactional, or in other words, both the way the world is and the way we study it. She refers to the former type of work as "constitutive because it speaks to the creation of fundamental ordering devices and categories" (p. 274) while the latter type is "interactional because it deals with the conflicts and accommodations that arise when competing natural and social orders are brought into confrontation" (p. 274). Furthermore, tensions arise when different ontological and epistemological orderings meet. The interactional approach looks at how people reconcile these competing epistemologies while constitutive analysis focuses on the emergence of new concepts. Although the STS version of coproduction is more explicitly focused on providing an alternative view of science and policy relations, it provides a way to look at how there are not strict boundaries between knowledge systems, but rather these distinctions are often subject to negotiation. The goal of using these two frameworks is ultimately to show how different states of knowledge are produced, sustained, or restricted, critiquing the claim that science is entirely socially produced while also rejecting a deterministic perspective. Bringing literature on coproduction of scientific knowledge to community-based monitoring in fisheries can help shed light on some areas of CBM research that is underexplored and help us understand how Tribal citizens play a role in coproducing knowledge about nature.

Because our research looks at how different knowledge systems are shaped by one another, we recognize the nuance in the usage of terms such as traditional knowledge (TK), Indigenous knowledge (IK), and local knowledge (LK). Translating one type of knowledge into another requires one knowledge system's cultural beliefs, assumptions, and practices to conform to another knowledge system's assumptions, beliefs, and practices (Bohensky and Maru 2011). When reflecting on knowledge integration, it is important to ask whose knowledge is new, whose is existing, and who decides this. For this reason, we move away from the notion of knowledge integration and move toward bridging knowledge systems where knowledge types are viewed as complementary. Epistemological pluralism should serve as the foundation for bridging knowledge systems in the context of natural resource management and research (Miller et al. 2008). All knowledge groups must be willing to reflect on their values and determine how their way of knowing the world influences judgments of validity in science. As Winona LaDuke states: "there is no way to quantify a way of life, only a way to live it" (LaDuke 1999:132).

\section{METHODOLOGY}

To understand how people produce knowledge within Alaskan salmon management, we employed a modified grounded theory, which included semistructured interviews. Grounded theory is a qualitative research method conceptualized by Glaser and Strauss (1967) as an inductive method for studying phenomena, which includes ongoing analyses of data. Charmaz's contribution to the grounded theory methodology explains that any study is an interpretive portrayal rather than a precise explication of the studied world (Charmaz 2006). Informed by a social constructivist perspective (Bryant 2002), Charmaz points out that not only do we interpret the meanings and actions of participants; they also interpret ours. This approach is appropriate for studying community involvement and collaboration because it allows the flexibility to encourage the participants' perspective to emerge from the data, rather than prescribing prior assumptions to the interaction with informants.

This qualitative interview study (Weiss 1994) includes semistructured interviews with six Alaska Native Tribal in-season managers, three ADF\&G in-season managers and researchers, and three federal managers and researchers, and five community stakeholders and monitors in the Kuskokwim region about their experience assessing data usability, defined simply as ease of use, ease of avoiding errors, efficiency of use, and satisfaction of use when producing and analyzing data to understand salmon ecosystems. Interview participants $(n=17)$ were asked questions about how data are useful for making decisions, and what data or information are seen as critical to making these decisions. Interviews were conducted between July 2018 and August 2019, then transcribed and thematically coded between January 2019 and November 2019.

Interviews were audio-recorded, transcribed, and coded with the Atlas.ti software. Coding was conducted following qualitative coding techniques (Saldaña 2013). Each interview was roughly 60 minutes resulting in 25 pages of text for a total of 425 pages of text. We developed our initial codebook by taking a first pass through the interviews, highlighting common themes with in vivo codes (Charmaz 2006). In vivo coding refers to the phrases used by participants, which can often reveal insider knowledge and shared perspectives. In this initial pass through the interviews, we sought to preserve the language used by participants moving on 
to more thematic coding in later phases. To gather an understanding of how communities are involved in management and how locally sourced data are utilized by management, we relied on interpretive inquiry through interviews. Interpretive inquiry emphasizes a phenomenological perspective and refers to the idea that a researcher's understanding of humans cannot be separated from their social and cultural world that is always in process (Morehouse 2012). Accordingly, because our questions are less focused on producing an objective measurement of program effectiveness, for example, and more focused on understanding how particular practices play out in Kuskokwim communities, this kind of inquiry is appropriate.

Our perspectives evolved throughout this project. The lead author began this work interested in the technicity of resource management with an expectation to find stark divides between Western scientific thought and Indigenous ways of knowing. Through an evolving appreciation of the negotiations that occur on the ground, she developed a more complex understanding of the relationship that management has with local Tribal people in the Kuskokwim region. Her understanding of the realities on the ground could not have been achieved without the guidance of the second author, who is Indigenous Ojibwe and Mexican-American and employed by ONC to oversee their fisheries programs. The remaining authors are non-Indigenous fishery scientists with extensive experience in the application of Western scientific methods to fishery management, and roughly a decade of experience with salmon management in the Kuskokwim region. Together, the authors represent multiple perspectives and collectively, were interested in the contribution CBM could make to better outcomes for salmon management and subsistence harvest. However, the authors do not speak Yup'ik and as such, some of the perspectives from participants for whom Yup'ik is their first language may be lost. This acknowledgement of our values is influenced by participatory design scholars (Borning and Muller 2012, Irani and Silberman 2013) who call for researchers to account for how their own perspectives influence research practices. This practice of stating positionality as researchers is becoming more common in fisheries research as well as evidenced by Reid et al. (2021)'s recent study.

\section{RESULTS}

Our key findings include three themes around data usability and community involvement: data usability involved trust in data stewards, required connecting to the participant's ontological commitments, and depended on infrastructural support, which facilitated interactions across different epistemologies. In this section, we outline these findings with quotes from interview data referring to participants as $\mathrm{P} 1, \mathrm{P} 2, \mathrm{P} 3, \ldots$ to preserve anonymity.

\section{Trust in data stewards as important to data credibility}

Data usability was closely tied with credibility, which was assessed as (1) an interpersonal matter of knowing the steward of data; (2) an issue of presence in the region; and (3) an issue of adherence to data standards. When asked about data usability, agency managers were largely focused on how to trust the data source; in some cases, this meant trust in an instrument, e.g., sonar or aerial survey data, or inconsistent weir data, while at other times it involved trust in a human data collector. In other words, trust in data was highly contingent on trust in data stewards not solely data curation practices such as adherence to standards, metadata recording, and instrument calibration.

Many participants brought up the importance of institutions for establishing trust in data stewards. One participant noted that the ONC program, "helped gain perspective and understanding where people can build trust between managers and be able to voice their opinions, especially at the [KRSMWG]... it spread like wildfire across the people and instead of being resistant, they were accepting (P1)." This aspect of interpersonal relationships and trust in data stewards is evident in concerns about statistical viability of data. Some participants mentioned programs like the USFWS Refuge Information Technicians (RIT) program, which involved local inhabitants surveying people they knew, as a way of achieving high quality and quantity data. Calendars were collected from people in villages as a way of keeping track of harvest. This kind of data was integral for management because it provided the baseline of harvest information in the delta. However, one participant noted that this data was not without its issues citing concerns about the statistical basis of the number because of the potential for reluctant participants to report on their harvest incorrectly.

Additionally, an unintended consequence of the RIT program was further disincentives for managers to go into the villages to get to know people. A primary limit to earning stakeholder trust was the lack of interpersonal connection with a common theme that past management regimes were more familiar and integrated into the region. Many interviewees were aware of local knowledge and recognized the benefit of "going to the villages" to retrieve local observations and to build trust. This relationship recursively influences management outcomes in terms of people accepting restrictions and being willing to offer observations. This was the pathway for management knowing locals, gaining trust with locals, and understanding different ways of knowing. One interviewee noted that a management issue "forced us to go into the villages and spend a lot of time [which] opened up the communications between the villages and FWS" (P7).

This reinforces findings that building of trust among communities increases the usability of the data in the sense that community members are more willing to participate, to share their knowledge, and to be seen as providers of credible data. This aspect of data usability suggests a particular type of coproduction aligned with the original formulation, which focused on the tacit knowledge gleaned from being present in a region. This suggests that coproduction can occur at an individual to individual level.

2. Mismatch between data usability and community engagement In interviews with managers, a common theme emerged around openness to other ways of knowing that see human and nature not as opposites but as one in the same. Of those interviewed, the most commonly considered form of community involvement included collaborative weirs, harvest monitoring surveys, voluntary adherence to restrictions, and local observations expressed in the KRSMWG meetings. Although not formally incorporated into management decision-making models, these observations offer local perspectives in-season while also enabling conversations across management groups, facilitating the opportunity for more informal transfers of knowledge. Although the majority of interview participants mentioned KRSMWG as 
Fig. 2. Visual representation of the themes related to defining local participation in data production. This networked diagram was generated from our codes in Atlas.ti. ONC, Orutsararmuit Traditional Native Council.

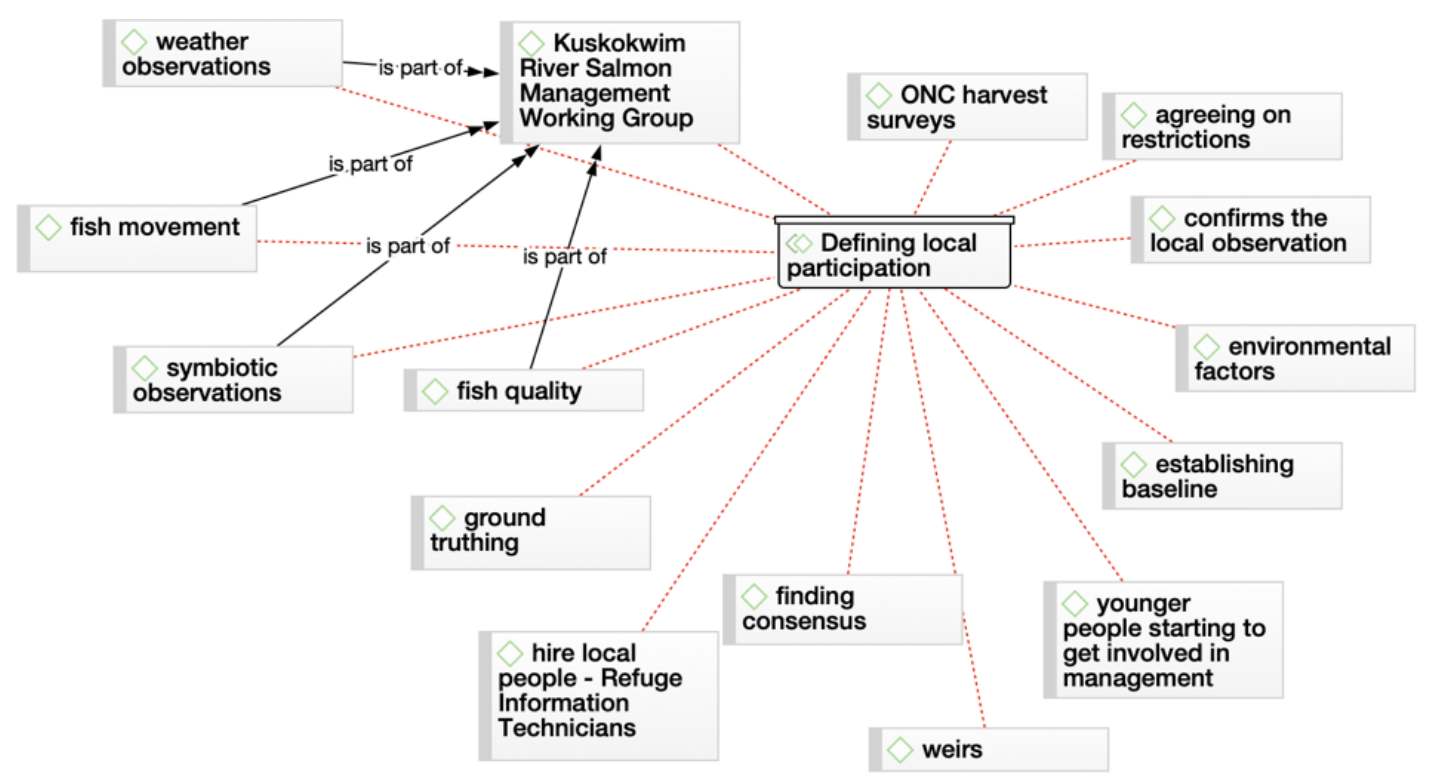

a way for locals to share knowledge with management, there was widespread disappointment in the lack of legally binding measures for the shared information.

The move to formalize local observations into data for management has evolved since statehood. One participant noted that, "In the early sixties, the bulk majority of what was known about salmon abundance, timing, distribution, was a combination of what [agency] folks have learned and what they learned from working specifically with folks who grew up in the area and fished those fish ... a lot of local traditional knowledge about just salmon in general, and then a tremendous amount of insight from catch data" (P5). This participant went on to note that the aerial survey program took off around the same time and that scientists "started to prioritize based on what they had seen and what they had heard from folks on the ground as to where they should put their effort" (P5).

Most participants mentioned the CBM program in terms of harvest monitoring while very few mentioned the age, sex, and length (ASL) sampling. There were myriad ways that participants defined local participation in addition to what types of observations were considered a part of KRSMWG (Fig. 2). Local observation was primarily defined as weather observations, fish quality observations, and as confirmation or validation that model outputs or predictions are correct. Locally sourced data most utilized by managers are mainly aligned with the literature reviewed for CBM fisheries work. In other words, the primary data type includes biological measurements of the fish, counts of fish, and harvest surveys. However, when asked what role local citizens can play in the production of data for management, major refrains were that observations about fish quality, environmental changes, and fish movement are major areas of expertise that local residents hold.
For example, after people complained about fish quality, biologists discovered that there were issues with warmer water and a disease, Ichthyophonus, affecting the fish. One participant pointed to the unlikelihood that managers "would have ever been aware of that without local people talking about it" (P7). Another example on run-timing and migratory patterns points to a more complex relationship and a bidirectional sharing of knowledge. Managers commented on how local observations about where people were catching fish led to speculation about the run, which coincided with data coming in from the test fishery. Those observations were "used as subjective support for what folks were starting to interpret the test fishery as saying (that the run was going to be late). So they had quantitative, numerical evidence of a possible late run and traditional knowledge and local input that made them more confident about the likelihood of a late run" (P8). This might be seen as a success story for local observations given the potential biological basis for the migratory pattern. However, research done in the lower portion of the river (Moses et al. 2019) found that fish traveling to the Kisaralik/Kwethluk rivers and passing through the Kuskokuak Slough enter at the same time meaning that they are not indicators of run timing for the aggregate stock. This example demonstrates the mutual shaping that occurs in the exchange of knowledge: On the one hand, the scientific relevance of the observation made it visible to management while the observation data refuted the potential explanation that catching more salmon on one side of the Kuskokuak indicated an early or late run.

This illustrates a common interview theme that local observations imply more than data about fish in terms of explicit management needs, but can offer a more comprehensive, holistic understanding regarding the health of the fishery when in exchange with other ontological and epistemological positions. This suggests the 
constitutive form of coproduction in that it points to the different ways that participants develop fine scale understandings of their environment, and how these ways of knowing influence one another.

\section{Infrastructural support for data usability}

Data usability was not only related to credibility and mutual knowledge exchange, but also emerged from infrastructural support. This was most clearly seen in examples of rapid change. In his ethnographic study of discourse in the lower Kuskokwim, Hensel (1996) notes the significant changes including everything from changes in climate to transportation to fish preservation techniques and the way in which subsistence practice is the thread that runs through the community. Across all participants, there was a strong theme of change in terms of climate and how this impacts strategies for conservation.

A major theme around adapting to later openers, and in particular, to drying fish in warmer weather emerged. Although there are concerted efforts at the local level to develop mechanisms for adapting to these changing conditions, e.g., bug netting, some participants explained how people have been slow to adapt. One proposed strategy was to diversify harvest as well as to take up more canning practices to deal with the growing challenges of drying fish later in the season. One participant noted, "the percentage of people in Bethel who preserve with canning is down to what it was back in 1968. Part of the reason is that the university had two agricultural extension agents working in Bethel with people [to learn about canning]. We even had one in Aniak and one in McGrath so the university was supporting that effort" (P11). This highlights the importance of having infrastructures in place that can help people adapt practices amidst a rapidly changing environment. In other words, the scope of data usage expands beyond meeting escapement goals, but considering the infrastructural challenges of changing practices and diversifying harvest.

Another theme related to infrastructural support emerged around funding cycles. One participant noted that the crash of chum $(O$. keta) and Chinook caused an influx of funding that "changed how the department and everybody else viewed fisheries and our understanding of fisheries" (P8). Poorly funded infrastructure can also intersect with data gaps as one participant noted that data often disappear because of lack of funding (P5). Another example of infrastructural support for knowledge production is ONC's involvement with in-season harvest monitoring in the Bethel area. This historical presence helped scaffold newer CBM initiatives by serving as a liaison between management and local and Tribal people, providing the knowledge infrastructure in the form of the survey instrument, long-term presence in the region, and shared training and resources.

Finally, challenges remain for incorporating local observations into formal management decision making. Although opportunities to voice concerns up and down the river through the KRITFC and the KSMWG meetings were largely considered successful, a challenge remains in terms of utilizing observational data within Western scientific perspectives. In reference to the KRSMWG observational data, one participant remarked, “...it's not used all that much. A lot of the reason is that the information is not perfect. But still, it gives people a chance to come along and feel like they've got a stake in the decision making ... some of the information is too specific" (P10). That specificity is "made general" by the number of participants in the meetings, but more importantly, the meetings serve as a place for community members to be heard. This challenge raises the need for more avenues for listening and incorporating other forms of unstandardized knowledge. More than integration or consensus, what is needed is a commitment to remaining open to learning based on different forms of knowledge.

\section{DISCUSSION}

Data usability was reported a number of ways: as an interpersonal matter of knowing who is stewarding the data, as an issue of presence in the region and exchange of knowledge, and as supported by knowledge infrastructure. Although the constitutive aspect of data usability occurred when new knowledge emerged, e.g., finding disease in the fish from warmer water and discovering migratory patterns for salmon in the lower river, the interactional included the disagreements and discussions about new knowledge produced. We have shown that knowledge is coproduced through interaction at multiple scales: individually, communally, and infrastructurally.

A common theme within literature on $\mathrm{CBM}$ in fisheries management is the various stages at which communities are involved in the research process. Models for implementing CBM configure scientific research as a linear process with a beginning and end, as well as the public as an a priori category rather than a collection of people who form around an issue. For example, Danielsen et al. (2009) put forward a typology for thinking through CBM in which the levels of engagement in monitoring range from no local monitoring to local monitoring done for and by the local populace. According to this typology, the level of local monitoring or engagement is directly correlated to the primary users of the data and is grounded in the assumption that agency researchers and local people have distinct if not conflicting needs or uses for data, or that their interests can be clearly separated and are not relational.

Although most government agencies are required to inform management with research-based evidence, this evidence has largely "been the product of biological models that hardly consider the wider institutional seascape of fisheries management" (Degnbol and McCay 2007:793). As such, collaboration between scientists, managers, Tribal citizens, and local residents does not necessarily imply a bridging across knowledge types. On the contrary, it may suggest that local participants are often required to serve scientific research by collecting data that only increases accuracy in predictions and does not change the outcomes qualitatively. However, the strength of statistical analysis or quantitative research paradigms should not be cast aside but rather, should be positioned within an Indigenous quantitative methodology (Walter and Andersen 2013). The case we have provided is an example of an attempt to bring together Indigenous knowledge and quantitative knowledge in ways that one does not subsume the other. Taking a coproductionist view of knowledge highlights the ways that interests are generated in the interstices of interactions between people. Our results indicate that coproduction occurs at different scales: not only between individuals, but also at the level of community and organization. 
The findings from this study suggest challenges common to CBM programs. Below, we offer some implications for designing infrastructure based on findings from our case.

\section{Establish institutional partnerships to bridge potential gaps} Although the CBM literature suggests clear delineations between interests of management and of the public, our research illustrated the relational quality of management and public involvement. In other words, we found that there is a mutual shaping that occurs in the exchange of knowledge rather than a unidirectional flow, and furthermore, that data and instrumentation are more than technical infrastructure, but also include and depend on knowledge infrastructure. For example, collaboration with other entities, such as ONC, USFWS, and ADF\&G has allowed for shared training and resources, thus providing for standardized and consistent sampling protocols and also reducing staff time and associated costs with hosting separate trainings. Local involvement in the development of the survey instrument, data collection process, analysis, and reporting has been successful in other CBM programs (Schemmel et al. 2016, Schemmel and Friedlander 2017) and can help people develop a better sense of ownership of the data collected in and by their community. Interviews highlighted that establishing manager partnerships in an area can enhance CBM legibility to management, as other forms of community-sourced data seem more trustworthy. For this reason, institutions like ONC, which has historically provided a liaison between Tribal citizens and governance regimes, are critical to program success.

\section{Formalize usage of local observational data}

As CBM programs evolve, greater emphasis on local coordination with continued scientific expertise will allow for ongoing local capacity building and data credibility. Moreover, many participants mentioned the local observations voiced in the KRSMWG and KRITFC meetings as an important way that communities are involved. Although the majority of the interviewees noted the utility of local observations for directing intuition, there remains gaps in more formalized ways for incorporating this type of knowledge and uncertainty into management procedures. Additionally, when people do not stay in the region there is a loss of collective knowledge. Future applications of these CBM programs should consider how to incorporate traditional, local, and Indigenous knowledge into more formal management decision making, particularly with respect to goals and objectives for management. As such, we see a key component to CBM programs moving forward as focusing on how to create long-term presence in a region and how to build relationships around knowledge sharing.

\section{Create more opportunities for technical training where there is interest}

Sociotechnical obstacles abound when working with scientific data tools. Although a few participants mentioned challenges with accessing the Bayesian statistical risk analysis tool frequently used in management models, the challenges were larger than technical with some participants noting that statistical analyses should not be the priority of all managers and researchers. There were a few participants who mentioned the information unevenness in not having the training to use scientific tools. However, others saw the expectation to use these tools as an added burden given the voluntary nature of participation.

\section{Design for the long term around short-term funding cycles or} funding that is catalyzed from disasters

The CBM program provides a short-term seasonal economic opportunity for a small number of people in a region where percapita income is near the lowest in the state (U.S. Census Bureau 2010) with the long-term goal of building future capacity for tribal member ownership of Kuskokwim fisheries research. However, long-term sustainability of the project remains uncertain because of inconsistent funding and low job retention when subsistence harvesting needs increase. Inconsistent funding and associated data fragmentation (Muir et al. 2013) may pose a major threat to the longevity of CBM programs and continued Tribal capacity building.

\section{CONCLUSION}

Beyond focusing on the individual incentives for participation, this study illustrates that collective engagement in the management of shared resources is possible with collective participation in, and acceptance of, group outcomes. The current CBM program is limited to collecting harvest data to inform inseason management decisions as a primary result of Chinook salmon conservation concerns. However, should Chinook salmon returns improve and the corresponding management structure change, it is unknown whether this resource-intensive monitoring program is sustainable and/or needed for fishery management (Staton 2018). Salmon return cyclically, such that one species such as Chinook salmon may experience low returns while another species experiences high returns. All salmon species are important to subsistence harvests, even though all salmon species do not have the same equivalency in utility or demand. Thus, lessons learned in applying CBM to Chinook salmon could have real application to other species that may exhibit declines in the future.

Our study shows that trust moves beyond implementing standardized protocols, but necessitates developing trust between managers and local and Tribal citizens as the exchange of information was critical for managers to consider the data collected by locals as trustworthy and for locals to consider management restrictions as trustworthy. Ultimately, this work may contribute to studies on Indigenous data sovereignty (Kukutai and Taylor 2016) exploring some of the ways that Tribal citizens have ownership, control, access, and possession of data in research. Furthermore, we exhibited that local observations of weather, fish quality, adaptation to harvesting practices, and emergent observations of fish health and habitat were supremely important in the region but not formally documented or directly utilized by all management entities. In sum, our research illustrated that involving village monitors beyond data collection has success in informing decision making in the long term. One recommendation in terms of research is to look more closely at how observations have changed over time in conjunction with management objectives. In other research, we are analyzing the KRSMWG meeting transcripts to identify themes that have emerged over the past 30 years. One finding we expect is that local residents might offer novel insights into different data to collect, one that speaks more closely to material practices of subsistence fishing and hunting. 
Responses to this article can be read online at: https://www.ecologyandsociety.org/issues/responses. $\mathrm{php} / 12117$

\begin{abstract}
Acknowledgments:
We would like to express our sincere gratitude to the anonymous reviewers for their valuable comments and helpful suggestions on a previous version of the manuscript. We are deeply grateful for the time that our research participants offered in allowing us to interview them. We also appreciate our colleagues, Shana Hirsch, Lauren Drakopolus, and Charlie Hahn, for engaging in discussion with us over these issues. This project has received funding from the Gordon and Betty Moore Foundation for the State of Alaska's Salmon and People (SASAP) project. We also thank the Human Centered Design and Engineering program at the University of Washington. This is contribution \#2021-05 of the Quantitative Fisheries Center at Michigan State University.
\end{abstract}

\section{Data Availability:}

The datalcode that support the findings of this study are available on request from the corresponding author, [SCI]. The datalcode are not publicly available because it would compromise the privacy of research participants. If data is requested, corresponding author [SCI] will share the anonymized data.

\section{LITERATURE CITED}

Baber, W. F., and R. Bartlett. 2005. Deliberative environmental politics: democracy and ecological rationality. MIT Press, Cambridge, Massachusetts, USA.

Beierle, T. C., and D. M. Konisky. 2000. Values, conflict, and trust in participatory environmental planning. Journal of Policy Analysis and Management 19(4):587-602. https://doi.org/10.1002/1520-6688 (200023) 19:4<587::AID-PAM4>3.0.CO;2-Q

Bohensky, E. L., and Y. Maru. 2011. Indigenous knowledge, science, and resilience: What have we learned from a decade of international literature on "integration"? Ecology and Society 16 (4):6. https://doi.org/10.5751/ES-04342-160406

Borning, A., and M. Muller. 2012. Next steps for value sensitive design. Pages 1125-1134 in CHI'12: Proceedings of the SIGCHI Conference on Human Factors in Computing, Austin, Texas. Association for Computing Machinery, New York, New York, USA. https://doi.org/10.1145/2207676.2208560

Bryant, A. 2002. Re-grounding grounded theory. Journal of Information Technology Theory and Application 4(1):25-42.

Buckland-Nicks, A., H. Castleden, and C. Conrad. 2016. Aligning community-based water monitoring program designs with goals for enhanced environmental management. Journal of Science Communication 15(03). https://doi.org/10.22323/2.15030201

Charmaz, K. 2006. Constructing grounded theory: a practical guide through qualitative analysis. SAGE, London, UK.
Connors, B. M., B. Staton, L. Coggins, C. Walters, M. Jones, D. Gwinn, M. Catalano, and S. Fleischman. 2020. Incorporating harvest-population diversity trade-offs into harvest policy analyses of salmon management in large river basins. Canadian Journal of Fisheries and Aquatic Sciences 77(6):1076-1089. https:// doi.org/10.1139/cjfas-2019-0282

Conrad, C. C., and K. G. Hilchey. 2011. A review of citizen science and community-based environmental monitoring: issues and opportunities. Environmental Monitoring and Assessment 176:273-291. https://doi.org/10.1007/s10661-010-1582-5

Danielsen, F., N. D. Burgess, A. Balmford, P. F. Donald, M. Funder, J. P. G. Jones, P. Alviola, D. S. Balete, T. Blomley, J. Brashares, et al. 2009. Local participation in natural resource monitoring: a characterization of approaches. Conservation Biology 23(1):31-42. https://doi.org/10.1111/j.1523-1739.2008.01063. $\underline{x}$

Danielsen, F., K. Pirhofer-Walzl, T. P. Adrian, D. R. Kapijimpanga, N. D. Burgess, P. M. Jensen, R. Bonney, M. Funder, A. Landa, N. Levermann, and J. Madsen. 2014. Linking public participation in scientific research to the indicators and needs of international environmental agreements. Conservation Letters 7(1):12-24. https://doi.org/10.1111/conl.12024

Degnbol, P., and B. J. McCay. 2007. Unintended and perverse consequences of ignoring linkages in fisheries systems. ICES Journal of Marine Science 64:793-797. https://doi.org/10.1093/ icesjms/fsm040

Dietz, T., E. Ostrom, and P. C. Stern. 2003. The struggle to govern the commons. Science 302(5652):1907-1912. https://doi. org/10.1126/science.1091015

Edwards, P., S. Jackson, M. Chalmers, G. C. Bowker, C. L. Borgman, D. Ribes, M. Burton, and S. Calvert. 2013. Knowledge infrastructures: intellectual frameworks and research challenges. Workshop, University of Michigan School of Information, Ann Arbor, Michigan, USA.

Emerson, R. M., R. I. Fretz, and L. L. Shaw. 2011. Writing ethnographic fieldnotes. Second edition. The University of Chicago Press, Chicago, Illinois, USA. https://doi.org/10.7208/ chicago/9780226206851.001.0001

Evenson, D. F., S. J. Hayes, G. Sandone, and D. J. Bergstrom. 2009. Yukon River Chinook salmon: stock status, harvest, and management. Pages 675-701 in C. C. Krueger and C. E. Zimmerman, editors. Pacific salmon: ecology and management of western Alaska's populations. American Fisheries Society, Bethesda, Maryland, USA.

Glaser, B. G., and A. L. Strauss. 1967. The discovery of grounded theory: strategies For qualitative research. Aldine, New York, New York, USA.

Hamazaki, T., M. Evenson, S. J. Fleischman, and K. L. Schaberg. 2012. Spawner-recruit analysis and escapement goal recommendation for Chinook salmon in the Kuskokwim River drainage. Alaska Department of Fish and Game, Fishery Manuscript Series 12(8):68.

Hensel, C. 1996. Telling our selves: ethnicity and discourse in Southwestern Alaska. Oxford University Press, Oxford, UK. 
Hirsch, S. 2020. Anticipating future environments: climate change, adaptive restoration, and the Columbia River Basin. University of Washington Press, Seattle, Washington, USA.

Irani, L. C., and M. S. Silberman. 2013. Turkopticon: interrupting worker invisibility in amazon mechanical turk. Pages 611-620 in CHI '13: Proceedings of the SIGCHI Conference on Human Factors in Computing Systems, Paris, France. Association for Computing Machinery, New York, New York, USA. https://doi. org/10.1145/2470654.2470742

Jasanoff, S., editor. 2004. States of knowledge: the co-production of science and social order. Routledge, London, UK. https://doi. org/10.4324/9780203413845

Johnson, N., C. Behe, F. Danielsen, E.-M. Kruümmel, S. Nickels, and P. L. Pulsifer. 2016. Community-based monitoring and indigenous knowledge in a changing Arctic: a review for the Sustaining Arctic Observing Networks. Final report to Sustaining Arctic Observing Networks. March 2016. Inuit Circumpolar Council, Ottawa, Ontario, Canada.

Kukutai, T., and J. Taylor, editors. 2016. Indigenous data sovereignty: toward an agenda. Australian National University Press, Canberra, Australia.

LaDuke, W. 1999. All our relations: native struggles for land and life. South End, Cambridge, Massachusetts, USA.

Lewis, B., W. S. Grant, R. E. Brenner, and T. Hamazaki. 2015. Changes in size and age of Chinook salmon Oncorhynchus tshawytscha returning to Alaska. PLoS ONE 10(7):e0132872. https://doi.org/10.1371/journal.pone.0130184

Miller, C. A., and C. Wyborn. 2020. Co-production in global sustainability: histories and theories. Environmental Science \& Policy 113:88-95. https://doi.org/10.1016/j.envsci.2018.01.016

Miller, T. R., T. D. Baird, C. M. Littlefield, G. Kofinas, F. S. Chapin III, and C. L. Redman. 2008. Epistemological pluralism: reorganizing interdisciplinary research. Ecology and Society 13 (2):46. https://doi.org/10.5751/ES-02671-130246

Morehouse, R. 2012. Beginning interpretive inquiry: a step-by-step approach to research and evaluation. Routledge, London, UK.

Moses, A. P., B. A. Staton, and N. J. Smith. 2019. Migratory timing and rates of Chinook salmon bound for the Kwethluk and Kisaralik rivers. Journal of Fish and Wildlife Management 10 (2):419-431. https://doi.org/10.3996/082018-jfwm-074

Muir, A. M., D. M. Leonard, and C. C. Krueger. 2013. Past, present and future of fishery management on one of the world's last remaining pristine great lakes: Great Bear Lake, Northwest Territories, Canada. Reviews in Fish Biology and Fisheries 23:293-315. https://doi.org/10.1007/s11160-012-9295-1

Nadasdy, P. 2005. The anti-politics of TEK: the institutionalization of co-management discourse. Anthropologica 47(2):215-232.

National Research Council. 2005. Developing a research and restoration plan for Arctic-Yukon-Kuskokwim (western Alaska) salmon. National Academies Press, Washington, D.C., USA. https://doi.org/10.17226/11080
Ostrom, E. 1990. Governing the commons: the evolution of institutions for collective action. Cambridge University Press, Cambridge, UK.

Ostrom, E. 2000. Collective action and the evolution of social norms. Journal of Economic Perspectives 14(3):137-158. https:// doi.org/10.1257/jep.14.3.137

Reid, A. J., L. E. Eckert, J.-F. Lane, N. Young, S. G. Hinch, C. T. Darimont, S. J. Cooke, N. C. Ban, and A. Marshall. 2021. "Twoeyed seeing": an indigenous framework to transform fisheries research and management. Fish and Fisheries 22(2):243-261. https://doi.org/10.1111/faf.12516

Saldaña, J. 2013. The coding manual for qualitative researchers. Second edition. SAGE, Thousand Oaks, California, USA.

Schemmel, E. M., and A. M. Friedlander. 2017. Participatory fishery monitoring is successful for understanding the reproductive biology needed for local fisheries management. Environmental Biology of Fishes 100:171-185. https://doi. org/10.1007/s10641-016-0566-X

Schemmel, E., A. M. Friedlander, P. Andrade, K. Keakealani, L. M. Castro, C. Wiggins, B. A. Wilcox, Y. Yasutake, and J. N. Kittinger. 2016. The codevelopment of coastal fisheries monitoring methods to support local management. Ecology and Society 21(4):34. https://doi.org/10.5751/ES-08818-210434

Schindler, D., C. Krueger, P. Bisson, M. Bradford, B. Clark, J. Conitz, K. Howard, M. Jones, J. Murphy, K. Myers, M. Scheuerell, E. Volk, and J. Winton. 2013. Arctic-YukonKuskokwim Chinook Salmon research action plan: evidence of decline of Chinook salmon populations and recommendations for future research. AYK Sustainable Salmon Initiative, Anchorage, Alaska, USA.

Staton, B. A. 2018. In-season harvest and effort estimates for the 2018 Kuskokwim River subsistence salmon fisheries during block openers. Project summary report, U.S. Fish and Wildlife Service, Yukon Delta National Wildlife Refuge, Bethel, Alaska, USA.

Staton, B. A., M. J. Catalano, B. M. Connors, L. G. Coggins Jr, M. L. Jones, C. J. Walters, S. J. Fleischman, and D. C. Gwinn. 2020. Evaluation of methods for spawner-recruit analysis in mixed-stock Pacific salmon fisheries. Canadian Journal of Fisheries and Aquatic Sciences 77(7):1149-1162. https://doi. org/10.1139/cjfas-2019-0281

Staton, B. A., M. J. Catalano, T. M. Farmer, A. Abebe, and F. S. Dobson. 2017. Development and evaluation of a migration timing forecast model for Kuskokwim River Chinook salmon. Fisheries Research 194:9-21. https://doi.org/10.1016/i.fishres.2017.05.003

Theobald, E. J., A. K. Ettinger, H. K. Burgess, L. B. DeBey, N. R. Schmidt, H. E. Froehlich, C. Wagner, J. HilleRisLambers, J. Tewksbury, M. A. Harsch, and J. K. Parrish. 2015. Global change and local solutions: tapping the unrealized potential of citizen science for biodiversity research. Biological Conservation 181:236-244. https://doi.org/10.1016/j.biocon.2014.10.021

U.S. Census Bureau. 2010. Selected economic characteristics: 2006-2010 American community survey 5-year estimates. U.S. Census Bureau, Washington, D.C., USA. 
Walter, M., and C. Andersen. 2013. Indigenous statistics: a quantitative research methodology. Left Coast, Walnut Creek, California, USA. https://doi.org/10.4324/9781315426570

Weiss, R. 1994. Learning from strangers: the art and method of qualitative interview studies. Free Press, New York, New York, USA.

Whitelaw, G., H. Vaughan, B. Craig, and D. Atkinson. 2003. Establishing the Canadian community monitoring network. Environmental Monitoring and Assessment 88:409-418. https:// doi.org/10.1023/a:1025545813057 
Appendix 1. Inclusion/exclusion criteria, coding variables, and sensitivities with a full list of papers reviewed.

We conducted the search from January to April 2018 using the following keywords in English: ["community based monitoring" OR "participatory monitoring"] AND ["Fisheries management" OR "fisheries monitoring" OR "fisheries assessment" OR "fisheries"].

Literature review inclusion/exclusion criteria

- Relevant studies included those implementing or reviewing community-based monitoring in fisheries management, sometimes more broadly focused review papers were included.

- We included manuscripts published prior to August 2017, when the review commenced.

- Only peer-reviewed articles were included.

- Only full text documents available online were included.

- Only studies published in English were included, given the larger body of literature is available in English, and the linguistic competency of the review team. Authors acknowledge the consequent bias introduced.

Coding Variables

1. Research questions/objectives

2. Region

3. Form of governance

4. Tools and methods used

5. What kinds of data

6. Public participation

And we look for relationships between:

1. Level of public participation

2. Level of engagement with policy makers and support for decision making

3. Overall purpose: system understanding, prediction/forecasting, decision support, or social learning/communication

List of papers reviewed

Citation

VanGerwen-Toyne, M., Gillis, D. M., \& Tallman, R. F. (2014). Statistical power: an important consideration in designing community-based monitoring programs for Arctic and sub-Arctic subsistence fisheries. Polar Biology, 37: 1435-1444.

Tawake, A., Vuki, V., \& Aalbersberg, W,. (2007). Fishing for Anadara: A case study of Ucunivanua village in Verata, Fiji Islands. Women in fisheries information bulletin Iss. 17: 2731.

Oviedo, A. F. P. \& Bursztyn, M. (2017). Community-based monitoring of small-scale fisheries with digital devices in Brazilian Amazon. Fish Manag Ecol, 24: 320-329.

Carvalho et al. (2009). Reliability of community-based data monitoring in the Olifants River estuary. Fisheries Research, 96: 119-128. 
Danielsen et al. (2007). Local participation in natural resource monitoring: a characterization of approaches. Conservation Biology, 23(1): 31-42.

McKenzie, L., Lee Long, WJ; Coles, R G. (2000). Seagrass-watch: community based monitoring of seagrass resources. Biologia marina mediterranea

Vol. 7, Iss. 2, (Mar 2000): 393-396.

Muir, A.M., Leonard, D.M., Krueger, C.C., 2013. Past, present and future of fishery management on one of the world's last remaining pristine great lakes: Great Bear Lake, Northwest Territories, Canada. Rev. Fish Biol. Fish. 23, 293-315.

https://doi.org/10.1007/s11160-012-9295-1

Vaoarinorotsihoara, L. A. \& Shawn, P. (2011). The role and effectiveness of community-based natural resource monitoring $(\mathrm{CBM})$ in a locally management marine area (LMMA), Madagascar. $7^{\text {th }}$ Western Indian Ocean Marine Science Association (WIOMSA) Scientific Symposium - Coping with Global change: Mombasa, Kenya.

Schemmel, E., Friedlander, A., Andrade, P., Keakealani, K., Castro, L.M., Wiggins, C., Wilcox, B.A., Yasutake, Y., Kittinger, J.M., 2016. The codevelopment of coastal fisheries monitoring methods to support local management. Ecol. Soc. 21.

Schemmel, E.M., Friedlander, A.M., 2017. Participatory fishery monitoring is successful for understanding the reproductive biology needed for local fisheries management. Env. Biol Fish 100, 171-185.

X. Zhu, A. Chapelsky, T.J. Carmichael, D.L. Leonard, E. Lea, R.F. Tallman, M. Evans, C. Podemski and G. Low. 2017. Establishment of ecological baseline metrics for integrated ecomonitoring and assessment of cumulative impacts on Great Slave Lake fisheries ecosystems. Can. Tech. Rpt. Fish. Aquat. Sci. 3223: x +58 p.

Stadel, A.V., Nelson, J.G., 1995. The role of citizen participation in ecosystem monitoring. Proc. Second Int. Conf. Sci. Manag. Prot. Areas.

Theobald et al. (2015). Global change and local solutions: Tapping the unrealized potential of citizen science for biodiversity research. Biological Conservation, 181: 236-244.

Burgos et al. (2013). A systems approach tomodeling Community-Based Environmental Monitoring: a case of participatory water quality monitoring in rural Mexico. Environmental Monitoring Assessment, 185: 10297-10316.

\section{Overview papers}

Bliss, J., Aplet, G., Hartzell, C., Harwood, P., Jahnige, P., Kittredge, D., Lewandowski, S. \& Mary Lou Soscia (2001) Community-Based Ecosystem

Monitoring, Journal of Sustainable Forestry, 12:3-4, 143-167, DOI: 10.1300/J091v12n03_07

Boyd, H. and Charles, A. (2006). Creating community-based indicators to monitor sustainability of local fisheries. Ocean and Coastal Management, 49: 237-258.

Conrad, C. and Hilchey, K. (2011). A review of citizen science and community-based environmental monitoring: issues and opportunities. Environmental Monitoring Assessment, 176: 273-291.

Cox, M., Arnold, G., \& Tomás, S. V. (2010). A Review of Design Principles for Communitybased Natural Resource Management. Ecology and Sociey, 15(4).

Johnson, N., Behe, C., Danielsen, F., Kruümmel, E.-M., Nickels, S., Pulsifer, P.L., 2016. Community-Based Monitoring and Indigenous Knowledge in a Changing Arctic: 74. 
Miller-Rushing, A., Primack, R., \& Bonney, R. (2012). The history of public participation in ecological research. Frontiers in Ecology and the Environment, 10(6): 285-290.

Pollock, R. M. \& Whitelaw, G. S. (2005). Community-based monitoring in support of local sustainability. Local Environment, 10(3): 211-228.

Fleener, C., Gofman, V., Peskov, V., Retter, G-B., Torikka-Gelencsér, R., 2004.

Community-based Monitoring - a discussion paper. Supporting publication to the CAFF

Circumpolar Biodiversity Monitoring Program - Framework Document. CAFF CBMP

Report No. 9, CAFF International Secretariat, Akureyri, Iceland, 21 pp.

Sharpe, A. \& Conrad, C. (2006). Community based ecological monitoring in Nova Scotia:

Challenges and Opportunities. Environmental Monitoring and Assessment, 113: 395-409.

Gruber, J. S. Key Principles of Community-Based natural Resource Management: A synthesis and interpretation of identified effective approaches for managing the commons.

Whitelaw, G., Vaughan, H., Craig, B., 2003. Establishing the Canadian Community Monitoring Network 10. 